\title{
Informing as a Discipline: An Initial Proposal
}

\author{
Zbigniew J Gackowski \\ California State University Stanislaus, CA, USA
}

\section{ZGackowski@csustan.edu}

\begin{abstract}
This paper presents an inquiry and a proposal of a structured way of thinking about informing as a separate field of scientific inquiry and practical endeavors and possibly a separate academic discipline. Informing is the science and art of practical endeavors to increase its effectiveness and efficiency; it is an interdisciplinary applied science with some components of universal validity, which according to Biglan (1979) mark pure science. It is a field with a defined model, a fundamental research question, a point of reference, a framework, observation points, and a way of measuring results. It has fundamental concepts, basic distinctions, a universal taxonomy of informing factors and their qualities, universal quality requirements, and priorities of research. It lacks, however, a clear division into sub-areas. To attain the status of a separate academic discipline, it needs further elaboration of sub-areas and a curriculum model that specifies competencies, an introductory course, prerequisite courses, and laboratories. This is an initial position paper written mainly from the operations management and decision sciences viewpoint with the purpose of eliciting challenge, critique, discussion, and suggestions for expansions in order to gradually develop a mutual consensus among those dealing with informing.
\end{abstract}

Keywords: Informing, informing science, informing discipline, field of inquiry

"Following the footsteps of the giants"

\section{Introduction}

Beginning with Nadler's (1982) terminology of work systems as used in industrial engineering, Gackowski (1982) stated that "informing systems are a class of work systems whose basic output is information that affects recipients' actions" (p. 108).

In 1999, Eli Cohen laid down the foundations of informing sciences and defined it as "the field of inquiry that attempts to provide a client with information in a form, format, and schedule that maximizes its effectiveness" (p. 5). Since that time, a separate field of informing science has emerged. It was fostered by the efforts of Eli Cohen, the founder of the Informing Science Institute, who established a tradition of annual international conferences, scientific and professional journals, and other forms of publication not horded but shared immediately without charge on the

Material published as part of this publication, either on-line or in print, is copyrighted by the Informing Science Institute. Permission to make digital or paper copy of part or all of these works for personal or classroom use is granted without fee provided that the copies are not made or distributed for profit or commercial advantage AND that copies 1) bear this notice in full and 2) give the full citation on the first page. It is permissible to abstract these works so long as credit is given. To copy in all other cases or to republish or to post on a server or to redistribute to lists requires specific permission and payment of a fee. Contact Publisher@InformingScience.org to request redistribution permission.
Web. The informing science framework encompasses (1) informing entitiesinformation sources; (2) communication channels; (3) entities informed-clients, users; and (4) information delivery systems.

This paper examines whether informing is a separate field of inquiry and practical endeavors and whether it is a separate academic discipline. Is informing science a science? Is it a separate field 
of scientific inquiry? Is it a lasting quest or it fades within a generation? Informing is a field of science and art of practical endeavors to increase its effectiveness; thus, it is mainly a human science. Nevertheless, information is objectively a physical phenomenon not limited to human communications. Where informing intersects with process control, it is a physical science. At least at the beginning, de-psychologization of information may facilitate the development of solid scientific foundations for informing; however psychology should never be excluded. The term science is used here as a system of knowledge in any field of inquiry with a well-defined scope; clear distinction of entities; phenomena and relationships among them, their taxonomy, paradigms of investigation, and theory. It entails unbiased, but mainly purpose-focused observations, systematic experimentation in pursuit of not only effectiveness but also of general truth, and the operations of fundamental laws. Informing as a science will be discussed within different taxonomies of academic disciplines as presented by Favero (2003), Kuhn (1996), and Biglan (1973).

Informing uses information technology (IT) widely, but its use is subservient to the purpose and circumstance of the efforts. IT is not explicitly at the forefront of informing as it is in computing (Denning et al., 1989, p. 1), computer-based management information systems (Ives, Hamilton, \& Davis, 1980, p. 1), or in most MIS textbooks. Informing contributes more and more in all realms of human endeavor and development. The $21^{\text {st }}$ century is marked as an age of information.

For instance, in operations, the role of informing emerges in full force. Besides the $4 \mathrm{Ms}$ (Methods, Machines, Materials, Manpower), information (I) is becoming a strategic critical success factor. Thus, the identification and exploitation of information sources (informing entities); methods; techniques and means of collecting, acquiring, and recognizing information values; and storing, processing, retrieving information, and its presentation to and utilization by users (entities informed) are the main concerns in planning and design of operations conducted by autonomously purposively acting humans, their organizations, systems controlled by artificial intelligence (robots), and any combination thereof.

Informing is interdisciplinary. It plays an important role in education, business, administration, politics, propaganda, and military science. Informing has matured enough to justify a more rigorous description of its intellectual substance, to provide a better sense of purpose, framework, and guidelines. This is an initial position paper written from the perspective of operations management and decision-making in operations, and therefore is of limited scope. Its purpose is to elicit challenge, critique, discussion, and suggestions for further expansion to gradually develop a mutual consensus about informing.

The main contributions of this paper are the initial articulations of

- the concept of informing

- a short description and definition of informing

- the paradigms of informing

- the initial division of informing into major sub-areas

- the schema of informing with major distinctions of its basic terms

- the universal conditions of effective informing

- the identification of major clusters of informing problems

- the identification of major problems with data and information in informing

- the place of informing within the major taxonomies of academic disciplines

- the discussion of informing from the perspectives of frameworks used in computing (Denning et al., 1989) and management information systems (Ives et al., 1980)

- the identification of what informing lacks to become a separate academic discipline 
For focused reading, key terms in paragraphs are in bold font, emphasis is in italics, highest emphasis is underlined, and terms followed by a definition are in bold italics. The author is particularly indebted to the final report of the Task Force on the Core of Computer Science, authored by Denning et al. (1989), with all its fine examples, which are used and adopted for informing.

\section{Informing}

\section{Paradigms}

It is proper to take an analogous approach to informing as to "Computing as a Discipline," by Denning et al. (1989). The fundamental question underlying all of computing is "What can be (efficiently) automated?" Such a question, as difficult as the answer may be, can be answered relatively objectively, while informing, by its very nature, is rarely to never objective. "Objective informing" is an abstraction that is as useful as the rarely-to-never attainable justice is. Among living entities, informing is always explicitly and/or implicitly biased by purpose or ignorance. Objective informing is an exception not a rule in the well-proven model of reality described by Schopenhauer in his opus vitae, "World as Will and Representation," (made available to English readers by Hamlyn (1980)). His model remains valid, if not for all philosophers, then certainly in all human endeavors where informing matters (Gackowski, 2006c).

When following the analogy of computing, and taking into account the essential differences between computing and informing, one may identify four major paradigms that provide a context for the definition of the discipline of informing: theory, modeling, planning, and design.

Theory for informing is rooted in philosophy in general, political philosophy, political science, sociology, psychology, operations research, management and decision sciences. Proceeding along the approach of Denning et al. $(1989$, p. 2), the informing paradigm consists of four steps that are followed in developing of a coherent valid theory: (1) characterize objects of study (definition), (2) hypothesize possible relationships among them (theorems), (3) determine whether the relationships are true (proof), and (4) interpret the results. One expects to iterate these steps when errors are discovered.

Modeling is an experimental scientific method. Here, the informing paradigm consists of four stages that are followed in the investigation of a phenomenon: (1) form a hypothesis, (2) construct a model and make a prediction, (3) design experiments and collect data, and (4) analyze results. One expects to iterate these steps when predictions disagree with experimental evidence.

Planning is rooted in operations research and operations management. It is a conscious pursuit for channeling the energy of the human will and life force into satisfying needs or fulfilling desires; otherwise, the energy is dissipated. Here, the informing paradigm consists of four stages that are followed before going into design of operations that address a specific problem or opportunity: (1) analyze needs, desires, existing or emerging problems, and opportunities; (2) set vision, mission, and goals; (3) set strategy, doctrines, and policies; and (4) set procedures. One expects to iterate these steps until the plan satisfies the will of the decision-making body.

Design is rooted in engineering, which in its advances and the growing affluence of population reaches out also for the arts. The informing paradigm for design consists of four steps that are followed when organizing operations to solve a given problem or to benefit from an emerging opportunity, for instance, that offered by technology: (1) state requirements, (2) state specifications, (3) design and implement the informing system, and (4) test the system for repetitive operations or conduct a mock test for a one-time campaign of operations. One expects to iterate these steps when results of tests reveal that the design of the system or campaign of operations may not satisfactorily meet the stated requirements. 
These four paradigms are distinct from one another because the competencies differ in those areas. Theory is concerned with the ability to describe and prove relationships among objects, events, and their attributes. Modeling or abstraction is concerned with the ability to use those relationships to make predictions that can be compared with reality. Planning is concerned with the ability to set up a strategy for long-term and current operations, including their mission, objectives, goals, doctrines, and policies. Design is concerned with the ability to implement specific instances of campaigns or systems of operations to attain specific goals. Applied mathematicians, informing scientists, planners, and designers generally do not have many interchangeable skills. They require not only different mindsets but also different professional preparations.

Informing sits at the crossroads among political philosophy, applied mathematics, operations research, operations management, business, and certainly education. The major binding force is a common interest in experimentation, planning, and design of effective informing.

\section{Description of Informing}

\section{Requirements}

The Oxford English Dictionary defines discipline as "a branch of learning or scholarly instruction." Referring to the requirements Denning et al. (1989) listed for computing, a good definition of informing as an academic discipline should:

1. be understandable by people outside the field

2. be a rallying point for people inside the field

3. be concrete and specific

4. elucidate the roots of the discipline

5. set forth a fundamental questions and significant accomplishments in each of its area

\section{A short definition}

Informing is the science and art of practical endeavors to increase its effectiveness and efficiency. It entails a systematic study of the content and form of symbolic representation of reality [data, information, significant relationships among them (associations and interdependencies), rules of procedure in reasoning and proceeding] from the perspective of the purpose and circumstances of informing, the algorithmic processes and the conditions of gathering and communicating these representations. The discipline includes theory, modeling, planning, and design of applications. The fundamental question underlying all of informing is "What can and how can informing contribute to human endeavors and advance mutual understanding?”

In the early 1980s, emphasis on informing emerged as a reaction to an overemphasis of information technology in management information systems (MIS) and information systems as taught to students of business and public administration. Students could recite jargon and technical terms but could not explain the actual purpose of informing and information systems. The related textbooks offer an oversimplified coverage of the fundamentals of the role of data, information, and knowledge in human endeavors. Current research supports this view. Huang, Lee, and Wang (1999) state, "Many best-practice reports witness that information technology alone is not the driver for knowledge management in companies today.... Information and knowledge experienced by members of an organization should be the focus, not the system or technology per se. Technology and systems ... are facilitators" (p. 4). Simply stated, technology is not an end in itself; it is only a means. The multifaceted aspects of informing have been completely inundated by elaborate descriptions of information technology in all forms - its potential, with case studies of 
its application, which are devoid of the fundamentals of informing and are used as examples of the technologies and not the problems they were supposed to solve.

The roots of informing extend into rhetoric, theory of communication, political philosophy and political science, journalism and mass communications, education, linguistics, marketing, psychology, sociology, human-computer communication, operations, organization, management, leadership, law, military science, etc. - a real interdisciplinary mix. Informing develops a theory and experimental methods that are applied later in planning, design, and implementation.

\section{Initial Sub-Areas of Informing}

Denning et al. (1981, p. 5) believe that, to qualify as a sub-area, a segment of the discipline must satisfy four criteria: (1) underlying unity of the subject matter, (2) substantial theoretical component, (3) significant abstractions, and (4) important design and implementation issues, as described in more detail under paradigms. Each area should be identified with a research community or a set of related communities that sustains its own literature.

This paper suggests the following sub-areas of informing: political philosophy, operations research, business and public administration, education, military science, health sciences, agriculture, and family and consumer science. As in computing, in informing, there are also some affinity groups where there is relevant literature, but these are not shown as separate sub-areas because they are basic concerns throughout the discipline of informing. For instance, information quality surfaces in all sub-areas. The same holds true for communications, knowledge and learning objects, human-computer communications, web page design, decision support, expert support, reliability, and security.

\section{Schema of Informing and Basic Distinctions}

Science requires a clear definition of the subject matter and a clear distinction of the objects subject to investigation (see Figure 1). The purpose of this section is to summarize the basic terminology used in informing, based mainly on a revised version of "Informing Systems in Business" (Gackowski, 2005a).

Informing deals with communication of significant symbolic representations of reality to others. Aspects of reality entail objects, events, their attributes, and relationships among them. They take the form of data and information values. Data values represent aspects of reality, which are given, known, and assumed true, and therefore are considered undisputable facts. Information values represent aspects of reality that are yet unknown or uncertain, to be collected, acquired, and recognized (weather conditions, attendance, etc.). In operations, data values and information values are disjoint sets of symbolic representations. The distinguishing criterion between them is whether there is any amount of information, as defined in the theory of communications by Shannon and Weaver (1949) associated with the received symbolic representation of reality.

This difference, innocuous as it appears for many and ignored by practically all MIS textbooks, always results in quantitative and/or qualitative differences in decision situations and operations. Thus, defined data values (and nothing more) never change decision situations, as they should have been incorporated into the available body of knowledge, the plan, and design of current action. While information values, as defined above, if only relevant and of significant impact, always change decision situations and operations with regard to the decision situation model, and/or the implementation of the decisions made and/or the results of the impacted operations. When an incoming signal or message confirms only the known status quo, it does not contribute anything to our current understanding of the situation. This holds true in any situation. 


\begin{tabular}{|c|c|c|c|c|c|}
\hline \multicolumn{6}{|c|}{ Informing Entities - Information sources } \\
\hline Passive & \multicolumn{5}{|c|}{ Active } \\
\hline \multirow{5}{*}{$\begin{array}{l}\text { (Reality ob- } \\
\text { served) }\end{array}$} & By nature & \multicolumn{4}{|c|}{ By design - on purpose } \\
\hline & \multirow{4}{*}{ (Emit signals) } & Sou & nown & \multicolumn{2}{|c|}{ Source unknown } \\
\hline & & \multicolumn{2}{|c|}{ Informing } & \multirow[t]{2}{*}{ Identifiable } & \multirow[t]{2}{*}{ Unidentifiable } \\
\hline & & Enforced & Not enforced & & \\
\hline & & $\begin{array}{c}\text { (Mandat. } \\
\text { Edu.) } \\
\text { Bias }\end{array}$ & (Media) bias & Bias & $\begin{array}{l}\text { High risk of } \\
\text { disinformation }\end{array}$ \\
\hline
\end{tabular}

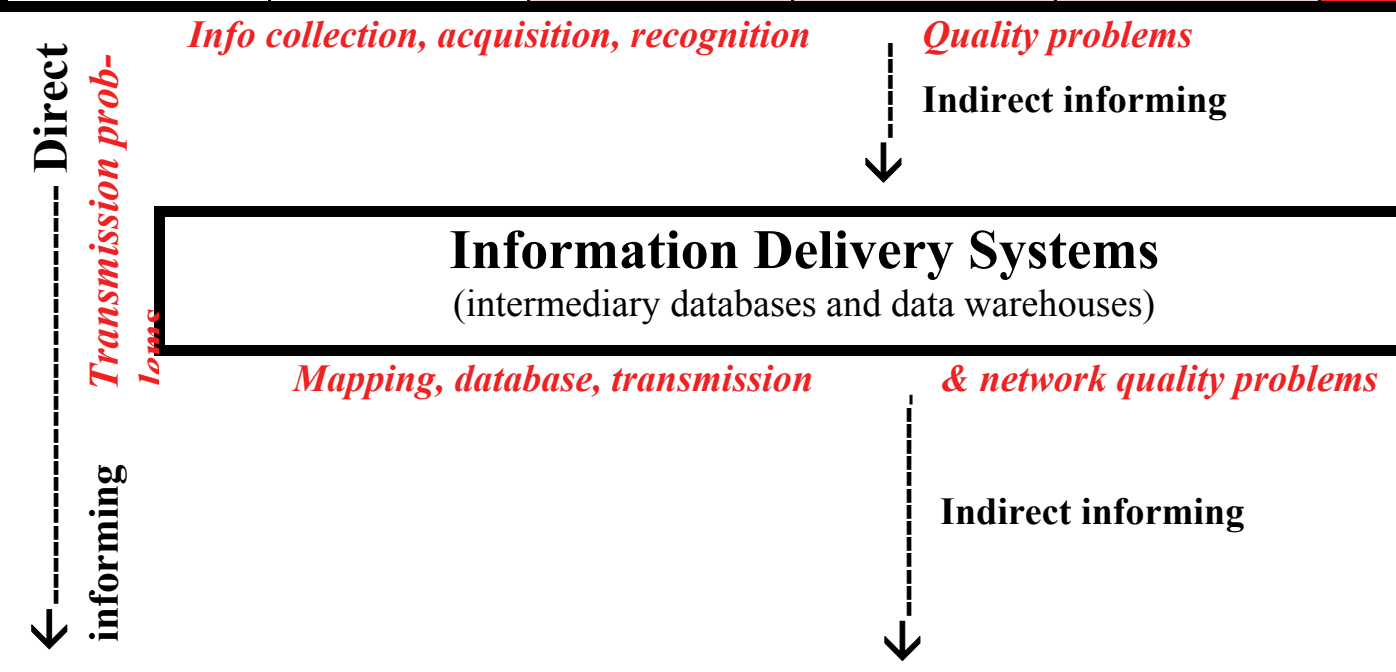

Information presentation quality problems

\section{Entities informed - clients, users}

(Autonomously functioning individuals, organizations, robots, targeted and/or seeking information)

\begin{tabular}{|c|c|}
\hline Inactive & Active \\
\hline (Temporarily not acting) & (Conducting operations) - high risk of disinformation and bias \\
\hline
\end{tabular}

Quality problems of operational utilization of information values

Figure 1. Provisional schema of informing

In rigorous science, ambiguity of terms may be tolerated. As long as neither quantitative nor qualitative differences have been identified between terms, they serve as synonyms. The differences identified above compel one to take exception even with the most popular and deeply rooted conventions and practice. It does not serve well the advancement of knowledge to make concessions for the sake of conventions and traditions that are of no scientific merit. Science does not develop by consensus but by evidence. Information must be significantly (with regard to its materiality) different from the known status quo to add anything to the current state of knowledge. Whenever there is a need for any kind of confirmation, it implies that there is uncertainty. 
The amount of information is a function of uncertainty. In view of decision sciences, after confirmation has occurred, decision-makers moved from the realm of stochastic to the realm of deterministic situations, which constitutes a qualitative change.

Informing entities may be active or passive. Passive informing entities are real objects and processes that yield information when observed, examined, counted, and/or measured. Active informing entities - sources by their nature or by design transmit, disseminate, or broadcast signals that may convey information. Some of the above may be widely known or be easily identifiable; others are completely unknown to the entities informed. Active-by-design informing entities such as senders or disseminators of information (educators, advertisers, professional information providers, politicians, preachers, etc.) try to affect the entities informed in an intended manner. Some of the informing may even be enforced (mandatory education or re-education camps), while most of it is not. Active-by-design informing is the vast field of communications.

Communication channels link informing entities with the entities informed. In communication channels, sets and sequences of signal transformations constitute the informing processes. Informing may be solicited and unsolicited. The links may be direct or indirect, which leads to direct or indirect informing. In direct informing, information flows directly between the informing entities (sources) and the entities informed. In indirect informing, intermediary manipulation of values takes place between informing entities and entities informed.

Within complex active-by-design informing entities and complex active entities informed, the division of labor leads to specialized sub-entities that deal with information collection, acquisition, recognition, storing, processing, and presentation, where data are organized in databases and/or data warehouses. They are specialized information and data delivery systems.

Entities informed (receiving clients, students, users, decision-makers) might be active or inactive. The active ones (marketing prospects, competitors, adversaries, voters, public, robotic devices, etc.) must conduct some kind of operations and act autonomously so that informing may make them behave differently than otherwise would be the case. Entities informed might be simple or composite entities, individuals, or organizations; they might even be robotic devices that are controlled numerically or by artificial intelligence. Initially and when viewed from the outside, the consequences of informing on the inactive entities informed may not be visible for a long time but in the long run may become significant once the latter act as the fruits of upbringing, education, training, indoctrination, and programming.

Entities informed may be targeted intentionally by disseminators of information, or they may actively gather information from sources. Hence, they may be interested in being provided with some information products or services. They may pay for being informed or seek only information that is offered seemingly free. They may also be inclined to enter into a dialog to refine the informing process.

There are two universal conditions for effective informing.

1. For informing to take place, there must be a difference in states of the informing entity and the entity informed with regard to the transmitted signals. In communications theory (Shannon \& Weaver, 1949), the difference is measured by entropy. (Entropy - a measure of the disorder or randomness in a closed system that consists of the informing entity (source) and the entity informed (client) - the number of bits necessary to transmit a message as a function of the probability that the message will consist of a specific set of symbols.) With no difference in the states of informing entities (sources) and the entities informed (users) (they know the same), their respective levels of entropy are also the same. After informing has occurred, the respective states at the extreme ends of the 
communication channels become equal. When such a change occurs, the received information values were not known by the entity informed before informing occurred.

2. In operations management, informing makes sense only as much as it eventually impacts actions and subsequent results either immediately or delayed. To be effective, information and data values or elements of knowledge must become operationally usable and then effectively operationally complete to trigger a transition of the state of operations (to act or not). (A data or information value becomes operationally usable when it jointly meets all of the universal [interpretable, operationally relevant, of significant impact, operationally timely available, actionably credible], and the situation-specific [for instance, exclusively available] mandatory quality requirements. Usability does not imply effectively usable.) Only then, the usable items become actually useful (Gackowski, 2005b); otherwise, they are potentially useful resources in waiting, which, if not used, become waste. (A usable data or information value may become operationally useful only as a member of an operationally effectively complete, task-specific cluster of required operationally usable data or information values.)

From the perspective of entities informed, after informing took place, the gathered (collected, acquired, and recognized) information values become the operating entities' data values and recognized elements of knowledge, which update common databases and knowledge bases.

\section{Additions to Cohen's Framework of Informing: (Point of Reference, Observation Points, Frame of Reference, Assumptions, and a Postulate)}

The purpose of this section is to summarize and articulate those aspects of informing that have not been explicitly stated in Cohen's framework, but which, for the sake of clarity, should be added. This list may not be complete.

A fruitful theory must refer to a well-defined point of reference, a frame of reference, observation points, and a yardstick for measuring the results of informing. The theory of informing involves the following:

1. Assumption 1: The main purpose (cost-effectiveness, for example) of operations is to serve as the main point of reference, and it is measurable. (What cannot be measured cannot be managed.)

2. Observation points are where observers are as:

a. Entities informed (users, clients) in passive informing,

b. Informing entities (information disseminators) in active informing by design, or

c. Both classes of entities when there is a relatively lasting relationship (business, social, personal) between them, because now both watchfully observe whether informing meets their expectations. (In informing, all observers, except sensors, are observing and participating interested subjects and agents in the middle of the situation - the informing framework, as viewed by John Dewey in his Theory of Inquiry (Magee, 2000, p. 293).

3. A frame of reference (circumstances the operations are subject to) of informing, which consists of

a. $\quad \mathbf{S N}$ - a set of variables sn that represent all significant states of nature and are beyond control of decision-makers (independent variables) 
b. D - a set of dependant variables $\mathbf{d}$ of significant materiality considered to be under the decision-makers' control (usually significant informing factors with their significant qualities - see the definition later in this section)

c. An adopted criterion of effectiveness of informing

d. Assumption 2: Decision-making employs rational and rule following choices as defined by March (1994); nevertheless, in the next refinement, it should account for irrational choices too.

4. As long as all of the above, including the assumptions, do not change, each variable

a. Is viewed and assessed the same way by rational decision-makers (observers)

b. Is bound by the same logic

c. Is subject to the same principles.

5. The postulate of general relativity of informing variables: Informing variables (dependent and independent) are seen, perceived, observed, and assessed the same as long the purpose and frame of reference remain unchanged even when rational observers change. Nevertheless, when such changes occur, they result in changes that affect how even objectively identical variables are seen, perceived, observed, and assessed by decision-makers. This is the essence of the all-pervasive principle of relativity of all variables in informing, operations, and decision-making. This postulate employs the analogy of inertial frames, which is used in theoretical physics. However, when informing supports decision-makers at strategic levels of management, contingency provisions should also be made for irrational choices. This is necessary because, as unreliable the nature of all designs is; irrationality is also a part of human nature. To simplify the following considerations, the independent variables sn and dependent variables $\mathbf{d}$ will later be simply referred to as variables $\mathbf{v}$ members of the set $\mathbf{V}=\mathbf{S N}+\mathbf{D}$.

6. A yardstick - a unit of any adopted measure of results of informing $\mathbf{M}_{\mathbf{R I}}$ under the assumption that $\mathbf{M}_{\mathbf{R I}}$ is a function of the purpose $\mathbf{P}$, all states $\mathbf{s}(\mathbf{v}) \mathbf{E} \mathbf{S}(\mathbf{v})$ of significant variables $\mathbf{v} \mathbf{E} \mathbf{V}$, and of all significant states of nature sn, formally

$$
\left.\mathbf{M}_{\mathbf{R I}}=\mathbf{M}_{\mathbf{R I}}(\mathbf{P}, \mathbf{s}(\mathbf{v})) \text { for all } \mathrm{s}(\mathrm{v})\right) \in \mathrm{S}(\mathrm{v}) \text { and } \mathrm{v} \in \mathrm{V} \quad \text { (Assumption 3) }
$$

In business, various criteria are used, such as net income after taxes, retained earnings, return on investment, return on equity, cost effectiveness, etc. In public administration, measurable or only observable results can be derived from the entity's mission. In military operations, they may be described by the expected tactical or strategic objectives. When cost effectiveness $\mathbf{C}_{\mathbf{E}}(\mathbf{I})$ of informing $\mathbf{I}$ matters, the percentage point of the ratio of the main purpose $\mathbf{P}$, divided by the cost $\mathbf{C}(\mathbf{I})$ of informing $\mathbf{I}$ over time, may serve as a unit of measure, then formally, $\mathbf{M}_{\mathbf{R I}}=\mathbf{C}_{\mathbf{E}}(\mathbf{I})=$ $\mathbf{1 0 0 *} \mathbf{P} / \mathbf{C}(\mathbf{I})$. This assumption implies that a relatively complete qualitative cause/effect diagram of operations (known also as a fishbone diagram) is available or can be drawn. It identifies the variables $\mathbf{v} \mathbf{e} \mathbf{V}$ of significant materiality in an informing situation, the required actions to implement the decisions made, and/or the results.

Factors are contributing significantly to results of operations. Informing factors may be

- already available, such as any available substance (material, tool, weapon), data, or elements of knowledge, and

- not yet available, to be acquired or even unknown and yet to be recognized, such as any additional information and any new element of knowledge. 
In this context, knowledge is what one knows or, broader, what society knows. It is represented by the available data values, the significant relationships among them, rules of procedure in reasoning and proceeding, including sequences of state transitions of robots. What one does not know, one tries to learn (collect, acquire, recognize). New information, new relationships, and new rules of procedure are added to what was known before and what has been learned and recognized as valid or only acceptable. Thus grows the body of knowledge of individuals and the entire society. Generally, after new states NS and new significant variables in informing $\mathbf{N V}$ have been recognized as valid and acceptable, the previous states $\mathbf{S}_{\mathbf{p}}$ of significant variables $\mathbf{V}_{\mathbf{p}}$ will be updated (augmented/reduced) to the respective current states $\mathbf{S}_{\mathbf{c}}$ of variables $\mathbf{V}_{\mathbf{c}}$. Formally,

$$
\mathbf{S}_{\mathbf{c}}=\mathbf{S}_{\mathbf{p}}+\mathbf{N S} \text { and } \mathbf{V}_{\mathbf{c}}=\mathbf{V}_{\mathbf{p}}+\mathbf{N V}
$$

Informing variables acquire potential materiality from the purpose, circumstances, and adopted criterion of effectiveness of operations. Materiality $\boldsymbol{M}\left(\boldsymbol{v}_{x}\right)$ of a specific variable $\boldsymbol{v}_{x}$ is defined as the difference in results of informing $\mathbf{R I}$, using $\mathbf{M}_{\mathbf{R I}}$ as their measure when acting with all variables $\mathbf{V}$ and without the specific variable $\mathbf{v}_{\mathbf{x}}$. Formally,

$$
M\left(v_{x}\right)=M_{R I}(V)-M_{R I}\left(V-v_{x}\right)
$$

Any significant informing variable $\mathbf{v} \mathbf{e} \mathbf{V}$ may represent a significant informing factor or any significant informing quality of such factor from the perspective of informing. It implies that each significant factor in informing must meet adequate quality requirements that are determined by the situation. Operation quality of an informing factor is defined by the states of its significant qualities that qualify it to play a significant role in informing. These states should be distinguishable. In general, quality can be represented as a vector of states of qualities in a multidimensional space. In research, necessary distinguishing qualities of entities facilitate compression of knowledge and a mastery of its complexity.

Generally, decision situations can be modeled into a decision-situation specification matrix as shown in Table 1. The components of decision situation are the possible states of the situation $\mathbf{s n}_{\mathbf{j}}$ (independent variables), potential choices or decision options $\mathbf{d}_{\mathbf{i}}$ (dependent variables), the foreseen outcomes $\boldsymbol{0}_{\mathbf{i j}}$, the utility function that assigns a utility value $u\left(\mathbf{o}_{\mathrm{ij}}\right)$ to each outcome $\mathbf{0}_{\mathrm{ij}}$, evaluation criteria of the outcomes, the decision makers, and finally the main purpose of operations $\mathbf{P}$. They were listed in the approximately ascending sequence of the expected extent of pervasiveness of their changes.

Table 1. Decision-situation specification matrix

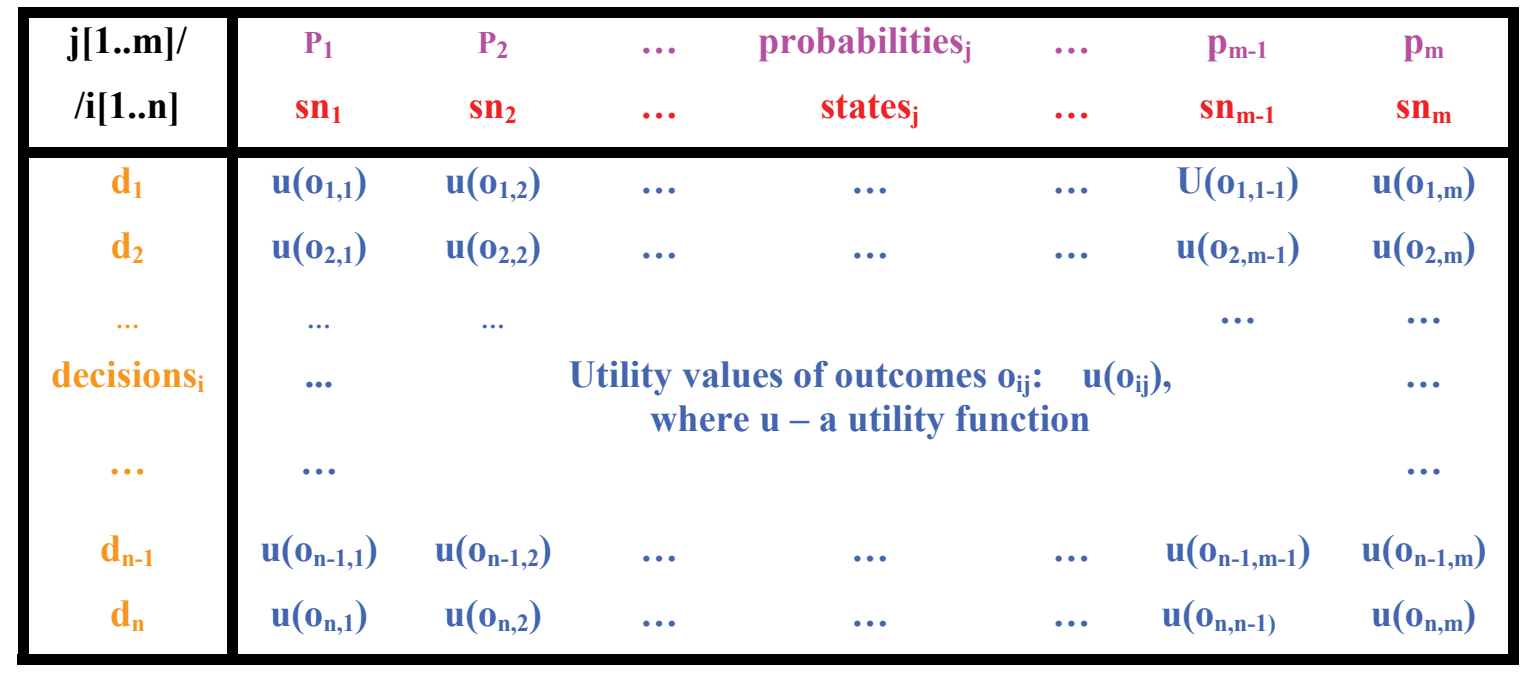


Outcomes $\mathbf{0}_{\mathbf{i j}}$, however, are rarely simple variables. They represent the current, foreseen, or attained state of reality in its various different but significant aspects. They may represent nothing more than a simple change in cost or dramatically different pictures of a scene before and after an accident, a village before and after a tornado hit, a field before and after the battle. Thus the outcome $\mathbf{0}_{\mathbf{i j}}$ is represented as a one dimensional array or vector of states of all significant aspects of reality, which are projected when decision $\mathbf{i}$ has been implemented in the state of nature $\mathbf{j}$.

An initial version of the situation model is built based on the available knowledge. At first, it is a purely static picture. The monitored changing reality (the system and its environment), however, requires a continuous adjusting of at least some of the major components of the model. The type, number, and degree of the changes is induced not only be the changing environment but also by the management, which adjusts the way it views the situation and reacts in response.

From the perspective of operations management, each change is communicated as a new piece of information $\Delta \mathbf{I}$, which the Shannon and Weaver's formula associates with some amount of information. An incoming symbolic representation of reality, which overlaps with what has been already known, does not change the model and its entropy, and thus convey zero amount of information. Data - the given, known, available do not change the situation. Only symbolic representations that convey some amount of information can do it.

Changes $\Delta$ of independent variables $\mathbf{s n}_{\mathbf{j}}$ and $\mathbf{p}_{\mathbf{j}}$ are viewed as the difference between their respective previous (") and current states (') caused by incoming information $\Delta \mathbf{I}$ can be defined respectively as $\Delta \mathbf{s n}(\Delta \mathbf{I})=\mathbf{s n}{ }_{\mathbf{j}} \mathbf{-} \mathbf{s} \mathbf{n}_{\mathbf{j}}$ and $\Delta \mathbf{p}(\Delta \mathbf{I})=\mathbf{p}_{\mathbf{j}_{\mathbf{j}}}-\mathbf{p}_{\mathbf{j}}$. Such changes invariably cause changes in the affected outcomes $\mathbf{0}_{\mathbf{i j}}$, their utility $\mathbf{u}$, and results of operations $\mathbf{M}_{\mathbf{R o}}$. Subsequently, decision makers may also change their tactic by changing the decision options from $\mathbf{d}_{\mathbf{i}}$, to $\mathbf{d}_{\mathbf{i}}$ ”. Summarily these changes will change the total outcome $\Delta \mathbf{o}(\Delta \mathbf{I})$ equal to the difference between the two vectors - the previous outcomes and the current outcomes, formally

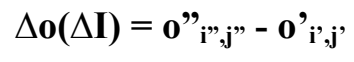

The above is the operation meaning of the received information $\Delta \mathbf{I}$ as viewed by the cofounder of pragmatism Peirce (1958) - the father of verifiability theory of the meaning, while $\mathbf{M}(\Delta \mathbf{I})=$ $\mathbf{M}_{\mathbf{R O}}\left(\mathbf{o}{ }_{\mathrm{i}}{ }^{,}, \mathrm{j},{ }^{\prime}\right)-\mathbf{M}_{\mathbf{R O}}\left(\mathbf{0}{ }_{\mathrm{i}, \mathrm{j}, \mathrm{j}}\right)$ is its materiality. Of course, the utility function $\mathbf{u}$ assigns different utility values to the respective differences with regard of each aspect of reality.

\section{Information Problems versus Data Problems in Informing}

The purpose of this section is to demonstrate that the essence of informing reaches far beyond presentation of data. Most researchers and practitioners seem to be oblivious to the very practical fact that, in the dynamic setting of operations,

- data values, as implied by the definition given and available, never can change a decision situation, while

- information values, if only significant, as something new, unknown, and not yet accounted for, always change the decision situation, and, more specifically,

- routine information about known factors change the situation mostly quantitatively unless the quantitative changes reach a critical point, causing qualitative changes, or

- potentially important information about factors that are new, significant, and not yet accounted for always qualitatively and quantitatively change the decision situation. 
The symbolic representation of reality is subject to changes that reflect the changing reality. Therefore, a system that monitors the changing real world must be established to keep the symbolic representations current. In routine operations, collection of the symbolic representations from the monitored reality takes place for known and rather well-established factors that impact the operations. They represent a relatively stable picture or representation of routine operations whose quasi equilibrium will eventually be disturbed. From the viewpoint of managing routine operations, the collected values are either

- routine data values only, because no changes have taken place and the status quo is preserved, or

- routine information values, because changes have taken place, with all the subsequent consequences. Information values that represent changes of known factors cause mainly quantitative changes; however, when they reach a critical point, they may also trigger qualitative changes. Once collected and recognized as valid, they become members of the updated set of data values.

The Schema of Informing (Figure 1) requires a distinction of routine information values and information values obtained from monitoring reality about potentially important factors that may impact operations. They are the realm of strategic management and decision-making. Potentially important information values and elements of knowledge after being acquired or recognized as valid, if only relevant and of significant impact or materiality, always qualitatively and quantitatively change the entire decision situation because they represent factors not yet accounted for. (Any new, valid, but not-yet-accounted-for information value requires a subsequent redefinition of the decision situation model. It certainly represents a qualitative change of the situation and, as such, is extremely unlikely without quantitative changes to the results.) Similar considerations also pertain to informing in education, propaganda, etc., where one must carefully weigh what is and what ultimately will be of importance versus the possible immediate effects.

Table 2. A taxonomy of always situation-specific elements of knowledge about operations from the perspective of informing

\section{K N O W L E D G E}

- a symbolic representation of reality in operations (objects, events, their identifiers and attributes, relations among them, and rules of procedure in reasoning and proceeding

\section{A T A}

about the given, known, available, assumed true operation factors; they never can change the existing decision situation - the status quo

\section{N F O R M A T I O N}

about the unknown or uncertain operation factors, not yet available, still to be acquired and always associated with some amount of information as defined by Shannon and Weaver (1949)

Routine Information
reflects changes about known op-
eration factors usually causing only
quantitative changes of results; they
are subject of routine operational
and tactical management

about still unknown factors, which if significant always result in qualitative changes of the existing decision situation; they are subject of strategic management

The discussed distinctions of data values from information values and, within them, routine information values and potentially important information values, profoundly differ from the definitions found in most MIS textbooks. For instance, "information as data shaped into a form that is meaningful and useful to human beings" (Laudon \& Laudon, 2007, p. 25), "information is data 
placed in a meaningful and useful context for an end user" (O'Brien and Marakas, 2008, p.596), and "information - data endowed with relevance and purpose" (Davenport, 1997, p. 9) ignore the well-established communication theory and the essential differences in decision-making.

In the mathematical theory of communication, information needs not be useful to be information. Usefulness never was a distinguishing attribute of information. Usefulness of phenomena is always contextual and never intrinsic to them. Data processing, as a deterministic process in its nature, can never yield any amount of information, anything unknown that could not be inferred from data. Nevertheless, it may present them in a more usable and effective manner for users but never as something that changes the situation. Of course, exploration of vast collections of data may yield something unknown. This, however, constitutes data mining, which is part of research, a quest for something unknown, which is not part of routine data processing.

The implications of these rigorous distinctions are vital for a clear separation of information quality (IQ) from data quality (DQ) problems, and quality problems with routine information values from those that pertain to the potentially important information values and new elements of knowledge, which usually are of strategic importance. This is not a common practice despite the fact that the differences are qualitative, tangible, and can be tested in any decision situation and any decision support system (DSS) and, thus, are of universal validity (Gackowski, 2006a). Quality problems with potential information values (as defined here) are of a distinctively strategic nature, while quality problems related to routine information values and routine data values are of a more technical and operational nature, as it will be shown in the examples below. In special circumstances, however, errors in routine data values may become deadly as well (Fisher, Chengalur-Smith, \& Wang, 2006, p. 5).

For example, in management information systems (MIS), one distinguishes two basic levels of informational support: (1) operations support information systems, and (2) management (support) information systems (MIS) (O'Brien et al., 2007). Quality requirements for operations support differ substantially from those required for management support. The latter support differs distinctively at the various levels of decision-making: non-managerial, operational or supervisory, tactical, and strategic.

Example 1: Transaction Processing Systems (Gackowski, 2006b). Management information systems depend heavily on transaction-processing systems (TPS). They are the main domain of the traditional data processing systems (DPS), automated data processing (ADP), or electronic data processing (EDP). Development of any higher-level MIS must begin with deployment of TPS because they capture, store, process, and retrieve transaction data for input to other business information systems. In pure versions, they keep track of the current state of the business reality and of the changes taking place. They use deterministic data values that are documented according to the Generally Accepted Accounting Principles (GAAP). At this level, one rarely distinguishes data from information. One does not yet ask why the data are needed, how they will be used, or to what business purpose they contribute simply because they are required by GAAP, which determines the quality requirements including: materiality, reliability (credibility), timeliness, currency, etc., as expected by the Financial Accounting Standard Board (FASB). The Generally Accepted Auditing Standards (GAAS) determine the necessary auditing procedures.

Example 2: Management Support Systems (Gackowski, 2006b). All of the data quality requirements for transaction-processing systems (TPS) are still valid but insufficient for management support. Here, a qualitative change in thinking about quality is necessary. Systems at the higher levels require a bold paradigm shift in thinking: (1) from the ontological toward the teleological view, (2) from the engineering requirements toward the end-user, requirements view, and (3) from the intrinsic and internal toward the external, task-specific view. The form and format of 
data/information presentation is usually differentiated for end users at different levels of decisionmaking. When it comes to the operations quality requirements of $\mathrm{D} / \mathrm{I}$ values,

- at the strategic level, the effective operational completeness of usable information values about urgent and dangerous threats and opportunities should be examined first;

- at the operations level, however, effective operational completeness of routine data values with the four direct secondary quality requirements, when economy matters, are of routine concern.

\section{Taxonomy of Decision Variables and Research Priorities}

The purpose of this section is to demonstrate to the readers of this initial proposal that there exists a hitherto unchallenged universal taxonomy of decision variables that suits informing well and facilitates a rational prioritization of research.

One of the first steps to knowledge is a clear distinction of entities (objects, qualities, states, relationships, phenomena, etc.) under investigation. Here, one needs a rigorous taxonomy of factors, states of their qualities, and the consequences of their changes. It is the beginning and the crowning of knowledge.

Textbooks and empirical studies list under different names a plethora of qualities or dimensions of data/information quality. One of the comprehensive ones in Wang and Strong (1996) mentions 179 different qualities. The major question, however, is how to examine those qualities in reallife situations, how to focus the attention of the examiners, and how to provide them with diagnostic guidelines. Which of them affect the situation results directly or indirectly; which are primary or secondary, necessary or optional; which are not fully attainable, therefore requiring one to learn to act with only some acceptable level of quality? Because they are many, these qualities require a systematic, uniform approach to research and their practical diagnostic examination.

Table 3. Schema of hierarchical impact-focused taxonomy of decision variables

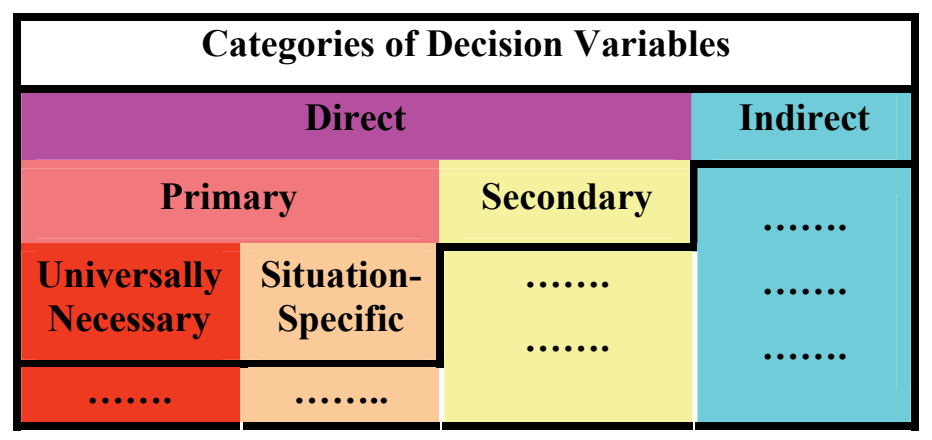

These concerns lead to a universal (applicable to all) taxonomy of allknown and not-yet-known data or information qualities and requirements related to them, which, together with research in progress on interdependencies among them, provides many clues in this regard. One should notice, however, that information qualities in informing are only a sub-class of qualities of any factors in operations including their qualities, and both are again a sub-class of variables in decision-

making. The same applies to their taxonomies. Thus, for sake of brevity, and keeping in mind the power of such an abstraction, the universal hierarchical disjoint and impact or result-focused (by type - qualitative, quantitative, or both) taxonomy will be presented simply as taxonomy of variables in decision-making. Table 3 schematically illustrates the defined taxonomy. It is natural, logically perfect, the strongest taxonomy of all, and it immediately facilitates an effective prioritization of researching decision variables (Gackowski, 2006a). This taxonomy is impact-focused because except for the last subclass, changes of variables of each class result in outcomes that belong to a separate class of outcomes. 
To facilitate comprehension, it is necessary to reemphasize that a variable, whether dependent or independent in decision-making, may represent any significant factor and any significant quality of such factor in any operations, not only in informing.

The universal hierarchical impact-focused taxonomy of sets of significant variables $V$ :

1. Subdivides the universe of variables $\mathbf{V}$ into direct and indirect or subordinate variables.

a. A change from the previous state $\mathbf{s}_{\mathbf{p}}$ to the current state $\mathbf{s}_{\mathbf{c}}$ of a direct variable $\mathbf{s}(\mathbf{d v})$, where dv $\mathbf{\epsilon} \mathbf{D V} \subset \mathbf{V}$ immediately affects the decision situation itself, and/or the actions to implement the decisions made, and/or the results of operations, which implies that they change the value of the adopted measure of results of informing $\Delta \mathbf{M}_{\mathbf{R I}}$, formally: $\left(\mathbf{s}_{\mathbf{p}}(\mathbf{d v}) \neq \mathbf{s}_{\mathbf{c}}(\mathbf{d v})\right) \Rightarrow\left(\Delta \mathbf{M}_{\mathbf{R I}} \neq \mathbf{0}\right)$.

b. A similar change of a state of an indirect variable s(iv)), where iv $\mathbf{e} \mathbf{I V} \subset \mathbf{V}$, as the name suggests, only indirectly affects the situation, because it determines or contributes to states of other indirect variables of a higher order (closer to the direct ones and at the extreme equal to direct variables). When $\mathbf{s}_{\mathbf{p}}$ and $\mathbf{s}_{\mathbf{c}}$ denote, respectively, the previous state and the current state of an indirect or direct variable, and $\mathbf{i}_{\mathbf{n}}$ and $\mathbf{i}_{\mathbf{n}-1}$ denote, respectively, indirect variables of $\mathrm{n}^{\text {th }}$-order and indirect variables of higher $(n-1)^{\text {th }}$-order [ for $n=1$ indirect variable of $0^{\text {th }}$-order is a direct variable $\mathbf{i}_{0} \mathbf{v}=\mathbf{d v}$ ]. It implies that a change of state of an indirect variable of $\mathrm{n}^{\text {th }}$-order causes a change of state of the related indirect variable of higher order $\mathbf{i}_{\mathbf{n}-\mathbf{1}} \mathbf{v}$ or at the extreme of a direct variable. Formally: $\left(\mathbf{s}_{\mathbf{p}}\left(\mathbf{i}_{\mathbf{n}} \mathbf{v}\right) \neq \mathbf{s}_{\mathbf{c}}\left(\mathbf{i}_{\mathbf{n}} \mathbf{v}\right) \Rightarrow\right.$ $\left(\mathbf{s}_{\mathrm{p}}\left(\mathbf{i}_{\mathbf{n}-1} \mathbf{v}\right) \neq \mathbf{s}_{\mathbf{c}}\left(\mathbf{i}_{\mathbf{n}-\mathbf{1}} \mathbf{v}\right)\right)$.

2. The direct variables subdivide into direct primary and direct secondary variables. The primary ones are Boolean \{true, false\}, exits or not; a requirement is either met or not.

a. Changes of states of the direct primary variables $\mathbf{s}(\mathrm{dpv})$, where $\mathbf{d p v} \mathrm{e} \mathbf{D P V} \subset \mathbf{V}$ always result in qualitative changes to the decision situations under consideration. Such changes result in adding or eliminating a variable from consideration, which is labeled $\Delta \mathbf{V}$. It must lead to a partial redefinition of the decision situation, which also has quantitative consequences. Formally: $\left.\left(\mathbf{s}_{\mathbf{p}}(\mathbf{d p v})\right) \neq \mathbf{s}_{\mathbf{c}}(\mathbf{d p v})\right)$ $\Rightarrow\left[\left(\mathbf{V}_{\mathbf{p}} \neq \mathbf{V}_{\mathbf{c}}\right)^{\wedge}\left(\Delta \mathbf{M}_{\mathbf{R I}} \neq \mathbf{0}\right)\right]$, where $\mathbf{V}_{\mathbf{c}}=\mathbf{V}_{\mathbf{p}}+\Delta \mathbf{V}$.

b. Changes to states of the direct secondary variables $\mathbf{s}(\mathrm{dsv})$, where dsv $\mathrm{e}$ DSV mainly quantitatively change the results of operations; hence, they may not necessarily be of significance $\left(\Delta \mathbf{M}_{\mathbf{R I}} \geq \operatorname{Min}\left(\Delta \mathbf{M}_{\mathbf{R I}}\right)\right)$. Nevertheless, if the subsequent quantitative changes reach a critical point - that is if the current state $\mathrm{s}_{\mathrm{c}} \mathbf{E}$ $\mathbf{C}(\mathbf{s}(\mathbf{d s v}))$ belongs to the set of critical states $\mathbf{C}$ - they may trigger a qualitative change of situations as well. Then they also become necessary or required. The secondary variables are mostly of an economic nature. If not only effectiveness, but also economy of results matters, they also may be necessary, although they may not be not universally necessary. Formally: $\left(\mathbf{s}_{\mathbf{p}}(\mathbf{d s v}) \neq \mathbf{s}_{\mathbf{c}}(\mathbf{d s v})\right) \Rightarrow\left[\left(\Delta \mathbf{M}_{\mathrm{RI}} \neq\right.\right.$ $\mathbf{0})^{\wedge}$ If $\left(\mathbf{s}_{\mathbf{c}}(\mathbf{d s v}) \boldsymbol{e} \mathbf{C}(\mathbf{s}(\mathbf{d s v}))\right.$ then $\left.\left(\mathbf{V}_{\mathbf{p}} \neq \mathbf{V}_{\mathbf{c}}\right)\right]$

3. The direct primary variables divide into those of universal necessity versus the situation-specific necessary ones that are determined by the circumstances. Changes to their states are Boolean \{true, false\} and always redefine the decision situation.

a. The direct universal primary variables are always necessary. Changes to their states s(dupv), where dupv $\mathbf{\epsilon}$ DUPV $\subset \mathbf{V}$, add or eliminate them from consideration. Formally: $\left(\mathbf{s}_{\mathbf{p}}(\mathbf{d u p v}) \neq \mathbf{s}_{\mathbf{c}}(\mathbf{d u p v})\right) \Rightarrow\left(\mathbf{V}_{\mathbf{p}} \neq \mathbf{V}_{\mathbf{c}}\right)$ 
b. The direct primary situation-specific variables are also necessary; however, they are situation specific, and therefore necessary, only under specific circumstances. Changes to their states s(dpssv), where dpssv $\mathbf{e}$ DPSSV $\subset \mathbf{V}$, also add to or eliminate variables from consideration; however they are not universally necessary only in a specific situation. Formally:

If (situation requires) then $\left(\mathbf{s}_{\mathrm{p}}(\mathbf{d p s s v}) \neq \mathbf{s}_{\mathrm{c}}(\mathbf{d p s s v})\right) \Rightarrow\left(\mathbf{V}_{\mathbf{p}} \neq \mathbf{V}_{\mathrm{c}}\right)$

(for instance restricted availability of information in a competitive situation).

Once a measurable point of reference and a universal hierarchical result-determined taxonomy of variables has been defined, one can rigorously prioritize most of the research in informing.

First, one should investigate those variables that directly impact the informing situation, the implementation of informing, and, finally, the ultimate results of informing. Among the direct variables, some certainly will be of a primary nature, which are always necessary (mandatory) and therefore universal. Other variables may also be necessary, but only situation specific. The remaining direct variables are of secondary nature. Changes of the direct primary variables always qualitatively and quantitatively change the outcomes. Changes to the direct secondary variables cause mainly quantitative changes to the outcomes; however, when the quantitative changes reach a critical point, they may cause qualitative changes as well.

All the remaining variables are the very numerous indirect ones, which affect the outcomes only by way of the direct ones. Of course, there exist long chains of prerequisite and functional dependencies of the direct variables on the indirect ones of the first and subsequent orders, which facilitate prioritization of research efforts. After an initial quantitative assessment of impact, one may prioritize them further in more detail. When the rules are rigorously observed, any research in informing qualifies as applied science, and all findings of a universal nature qualify as pure science. Thus, research in informing, as classed above, eliminates fuzziness that is evident in the Ives et al. (1980) Framework of Research in MIS, which will be discussed next.

Components of the proposed framework and model for research in informing are anchored in logic principles. No general framework or model can be proved, but it can be tested and disproved as shown by Hume and asserted again by Popper in his Logic of Scientific Discovery (1959) (Magee, 2000, p. 115 and p. 223). They do not require empirical validation except for coming up with examples to the contrary. Then a revision is unavoidable. The proposed model and framework, however needs to be discussed, challenged, and criticized by the community of actual and potential researchers in informing because this is the only guarantee of progress. In other words, it needs their approval after all indispensable revisions have been made.

\section{Ives et al. Framework for Research in C-B MIS}

The Framework for Research in Computer-Based (C-B) Management Information Systems (Ives et al., 1980) is the closest proxy of informing although it does not directly address informing per se. It is not merely a piece of research done in 1980; it served as the recognized framework for hundreds of doctoral dissertations in MIS and, as such, should not be ignored.

Any model that is capable of becoming a rallying point for a broader community of researchers and of yielding research results of lasting validity should entail an explicitly or implicitly welldefined point of reference, observation point, and frame of reference. Research about informing should encompass any kind of informing and not be limited only to computer-based informing, as was that of Ives et al. The main object of interest should be informing per se in the light of the fundamental question in informing and not the information systems that support, serve, and mediate informing. Such rigor is missing in their framework. 
The Ives et al. framework entails three types of variables: environmental variables (constraints and resources), information subsystem characteristics, and process variables (performance measures). Certainly, the environmental variables are always factors in all endeavors. It may be interesting to review them from the perspective of informing. Therefore, the three types of variables can be relabeled as environmental, informing, and performance variables.

Environmental variables in informing: When one follows Ives et al. with regard to the environmental characteristics, one can say that they also represent the resources, constraints, and opportunities that impact informing. Four classes of environmental variables were delineated: External environment, organizational environment, user environment (entities informed), and development environment.

The external environment includes legal, social, political, cultural, economic, educational, resource, and industry/trade considerations. The organizational environment is marked by management's philosophy, mission, strategy, structure, and goals. The user environment entails the primary acting entities informed (decision-makers, actors, agents), their tasks, staff members, and surroundings. The development environment consists of the development methods and techniques, design personnel and their characteristics (education, experience, etc.), and the organization and management of development.

The informing variable: The second factor of importance is the model of informing (the information subsystem by Ives) that entails the set of usable and useful values of symbolic representation (data, information, and elements of knowledge) with the pertinent quality requirements over their entire multidimensional space, decision models, and algorithms used.

Performance variable: The primary prerequisite for attaining meaningful quantitative research and practical results is defining a measurable, testable purpose of informing. Reasonable measures of the performance of informing are effectiveness, economy, cost effectiveness, or expected cost effectiveness of informing. In computing, storage space and computing time were defined as performance measures, including their tradeoffs.

\section{General Comments about the Ives et al. Framework}

The framework by Ives et al. (1980) covers only some elements of a vaguely defined frame of reference, leaving the rest (purpose and observation points) to researchers' discretion; thus, it provides no objective criteria for assessing progress within the discipline. Because it is not anchored in proven logic principles, it invites purely empiricist research. In "The Poverty of Empiricism," Mende (2005) warned that "in producing explanatory theories empirical methods are inherently useless" (p. 189).

When carefully examined, the three classes of variables that explicitly pertain to the information subsystem try to address the $179+$ dimensions of data/information quality identified a decade ago by Wang and Strong (1996). They are labeled information subsystem variables, which are today's equivalent of attributes or dimensions of information quality. In most research, they are listed and treated as independent variables despite the fact that they are interdependent in many ways (Gackowski, 2004, 2005b). This alone may lead to fruitless empirical studies, which, if not carefully designed, rarely prove anything decisively, as it will be shown later.

The process variables proposed by Ives et al. (1980, p. 919) are very controversial and overlap with variables of information quality. This overlap indicates only that there was a foreboding of the problem of information quality. For instance, one may notice "accuracy, source, age, scope, level of aggregation, and time horizon" among the information subsystem content variables, including "presentation form" on the one hand and "time of presentation" variables and the "turnaround times, response time, availability, error rates" among the operations process variables on 
the other hand. All of them are today the known dimensions of data and information quality that are subject to a rigorous universal hierarchical disjoint impact-focused taxonomy (Table 3).

The definitions and description seem not to be coherent. "The process variables represent measures of the interactions" (between the information system and the environments), while Exhibit 7 in Ives et al. (1980), Five Categories of Information System Research, explains the PROCESS VARIABLES as (Performance Measures). The cited approach leaves the impression that MIS is an autonomous phenomenon in its own right, which requires research, but is devoid of any higher-level purpose. There is a single hint to "an effect on productivity" and an undefined "decision-making quality." There are, however, many references to "quality of work life," "quality of life and satisfaction of secondary users, and the service to users," and "participation, support, and satisfaction with the development effort." These statements suggest that, by Ives et al., MISs are developed, operated, and used for the welfare of the participants, with no focus on the main business purposes, which were never even mentioned.

Ives et al. claim that a major use of their framework is to generate relevant testable hypotheses for MIS research, and they offer examples. Summarily, they confirm Mende's (2005) paper, "The Poverty of Empiricism" (p. 189). Only four (1.2\%) of the 331 dissertations "specifically develop performance measures for the development, operations or use processes"; "descriptions have been over used and discovery research has been underutilized" (Ives et al., 1980, p. 930).

Now that 25 years have passed since the model was published, it would be interesting to study how effective the framework has been. It would likely be a waste of time and depressing for young people who are pursuing doctoral degrees. Without much risk, one may venture to generate the following double-whammy hypothesis: Over the last 25 years, as far as anecdotal evidence reflects reality, this framework was likely very productive in generating many well-defended doctoral dissertations; nevertheless, only a few of them, if any, yielded research results of lasting validity in the discipline. A cursory survey of MIS textbooks seems to confirm it. If any reader can find any example to the contrary, it should be carefully considered.

There is, however, a classic and representative example of what real break-through contributions to MIS suffer from authors of MIS textbooks. In 1968, Kofler defined and published the concept of utility value of information $I$ as determined by the difference in the value of results of operations when acting with and without that information. In 1970, Alter defended his unpublished Ph.D. dissertation, titled "A study of Computer Aided Decision-making in Organizations," at the Massachusetts Institute of Technology. Judging by the reputation the Sloan School of Management enjoys in business disciplines (in management information systems, production \& operations management, and quantitative analysis/methods rated number one) by the deans and senior faculties at business programs accredited by the Association to Advance Collegiate Schools of Business ("Special Report," 2006), he is one of the brightest. Reviewers of a critique of MIS textbooks as overly technology laden but lacking the fundamentals about data and information (Gackowski, 2004) cited the textbook by Alter as an exception. Nevertheless, more than 30 years after the concept of utility value of information was published, and more than 25 years after Alter defended his Ph.D., he also authored a textbook about MIS, where one can easily find that the utility value of data/information is a concept that is "more elegant than practical" (Alter, 2002, p. 162). It demonstrates how fundamentals of informing are presented to students of MIS, and it is in one of the best textbooks in this field.

\section{Informing Science in Other Classifications of Disciplines}

The purpose of this section is to provide the readers of this initial proposal with other acknowledged perspectives of viewing academic disciplines. According to Favero (2003), four frameworks of classing academic disciplines have drawn much of the focus of empirical studies of dis- 
cipline differences: codification, level of paradigm development, level of consensus, and the Biglan Model (1973).

Codification refers to the condition whereby knowledge can be consolidated or codified into succinct and interdependent theoretical formulations. It describes a field's body of knowledge as opposed to behavioral attributes of scholarly activity. Codification implies a high-low consensus concept to such a degree that it is considered a function of codification; thus, they overlap. If the community of the Editorial Board of Reviewers and other scholars of informing could agree on the initial definition of informing and the presented Model of Informing (Figure 1), one could rightly claim that informing attained a high level of codification and, by the same token, a high level of consensus.

Paradigm development, as first defined by Kuhn (1996), refers to the extent to which a discipline possesses a clearly defined "academic law," an ordering of knowledge, and associated social structures. "Mature sciences" have clear and unambiguous ways of defining, ordering, and investigating knowledge. Again, the terms paradigm development and consensus are thought to be interchangeable, as they describe a common dimension of disciplinary fields: the extent of agreement about structure of inquiry and the knowledge it produces. If we could agree on the proposed paradigms of informing ("theory, modeling, planning, and design"), guided by the fundamental question underlying all of informing ("What and how informing can contribute to human endeavors and advance mutual understanding"), we could rightly claim that informing exhibits a high level of paradigm development.

Consensus implies unity of mind concerning elements of social structure and the practice of science, including theory, methods, techniques, and problems. The indicators of consensus in a field are absorption of the same literature, similar education, professional initiation, and cohesiveness in the community that promotes relatively full communications and unanimous professional judgment on scientific matter; and a shared set of goals, including the training of successors. According to the above indicators of consensus, informing science can claim a shared set of goals. Informing heavily promotes full communication of results and possesses well-developed venues for publishing the research results. If an agreement could be reached about the definition, paradigms, and fundamental question, informing may claim the existence of a unanimous professional judgment of scientific matter.

The Biglan Model (1973) was derived from taxonomy of academic disciplines based on the responses of faculty from a large public university and a private liberal arts college regarding their perceptions of the similarity of subject matter areas. The taxonomy by Biglan uses three dimensions: (1) the degree to which a paradigm exists (paradigmatic or pre-paradigmatic or hard versus soft disciplines), (2) the extent to which the subject matter is practically applied (pure versus applied), and (3) involvement with living or organic matter (life versus non-life systems). Informing certainly fits into Biglan's clusters of academic areas as a paradigmatic, hard applied field of inquiry on mainly life systems.

Again, when using Becher's (1989) comparative review of discipline differences, informing at its current state belongs to the "hard-applied" discipline group. With regard to "nature of knowledge," informing is purposive, pragmatic, and concerned with mastery of the environment resulting in products/techniques. However, informing within the realm of routine information also contains elements that may class it partially into the "hard-pure" group. It is so because the "Nature of knowledge" about informing is also cumulative, concerned with universals, and resulting in discovery and explanation. 


\section{Conclusions}

This paper proposes a structured way of thinking about informing as a separate field of scientific inquiry and a separate academic discipline. Informing, when defined from the adopted perspective, is the science and art of practical endeavors in increasing its effectiveness and efficiency; it is an interdisciplinary applied science with some components of universal validity that mark pure science (Biglan, 1973). It is a field with a model, a fundamental research question, a point of reference, observation points, and units of measurement. It entails fundamental concepts, basic distinctions, a frame of reference, a universal taxonomy of basic factors and functional interdependencies among them, six universal quality requirements, and clear priorities for research. It lacks, however, a clear division into sub-areas. When applying the same criteria to informing as to computing (Denning et al., 1989), to attain the status of a separate academic discipline, informing needs elaborations of its subareas and a curriculum model that specifies competencies, an introductory course, prerequisites courses, and laboratories. At present, informing certainly constitutes only a separate field of research and practical endeavors.

This paper presents an initial model and several additions to the current framework for informing by Cohen (1999), with the purpose of eliciting critique, discussion, challenges, and suggestions for extensions from the community of researchers who are actively conducting research in this field or who are interested in doing so.

\section{References}

Alter, S. (2002). Information systems - Foundation of e-business. Upper Saddle River: NJ: Prentice Hall.

Becher, T. (1989). Academic tribes and territories: Intellectual inquiry and the cultures of the disciplines. Bury St. Edmunds, England: Society for Research into Higher Education, Open University Press.

Biglan, A. (1973). The characteristics of subject matter in different academic areas. Journal of Applied Psychology 57(3), 204-213.

Cohen, E. (1999). Reconceptualizing information systems as a field of the transdiscipline informing science: From ugly duckling to swan. Journal of Computing and Information Technology, 7(3), 213-219. See: http://inform.nu/WhatsIS.htm

Davenport, T. (1997). Information ecology - Mastering the information and knowledge environment. New York: Oxford University Press.

Denning, P. J., Comer, D. E., Gries, D., Mulder, M. C., Tucker, A., Turner, J., \& Young, P. R. (1989). Computing as a discipline (final report of the task force on the core of computer science), Communications of the ACM, 32(1), 9-23.

Favero Del, M. (2003). Academic disciplines. Encyclopedia of Education $\left(2^{\text {nd }}\right.$ ed.). New York, NY: Macmillan Reference.

Fisher, L., Chengalur-Smith, S., \& Wang, R. (2006). Introduction to information quality. Cambridge, MA: MIT Information Program.

Gackowski, Z. J. (1982). An approach to categorization of information systems. Proceedings of the ASIS (American Society for Information Science) Annual Meeting, October, 17-21, 1982, Volume 19, Columbus, $\mathrm{OH}$.

Gackowski, Z. J. (2004). Logical interdependence of data/information quality dimensions-A purposefocused view on IQ. Proceedings of the Ninth International Conference on Information Quality (ICIQ04), November, 5-7, 2004, Cambridge, MA. See:

http://www.iqconference.org/ICIQ/iqdownload.aspx?ICIQYear=2004\&File=LogicalInterdependence.p $\underline{\mathrm{df}}$ 
Gackowski, Z. J. (2005a). Informing systems in business environment: A purpose-focused view," Informing Science Journal, 8, 101-122. Retrieved June 27, 2005, from http://inform.nu/Articles/Vol8/v8p101-122Gack.pdf

Gackowski, Z. J. (2005b). Operations quality of information: Teleological operations research-based approach, call for discussion. Proceedings of the 10th Anniversary International Conference on Information Quality -ICIQ-05, November, 4-6, 2005, Massachusetts Institute of Technology (MIT), Cambridge, MA. See:

http://www.iqconference.org/ICIQ/iqdownload.aspx?ICIQYear=2005\&File=OperationsQualityofData nInfo.pdf

Gackowski, Z. J., (2006a). Impact of information and its quality on decision situations: An analytical inquiry, Proceedings of the 2006 Annual Meeting of the Northeast Decision Sciences Institute-NEDSI 2006, March 30 - April 1, 2006, in San Juan, Puerto Rico.

Gackowski, Z. J., (2006b). Intrinsic and internal vs. external view of DQ/IQ: A case for relativity, Proceeding of the 17th International Conference of the Information Resource Management Association IRMA2006, Washington, DC, May 21-24, 2006.

Gackowski, Z. J., (2006c). Quality of informing: Disinformation and bias - Philosophical background and roots, Journal of Issues in Informing Science and Information Technology, Volume 3(2006). See: http://informingscience.org/proceedings/InSITE2006/IISITZbig250.pdf

Hamlyn, D. W. (1980). Schopenhauer: The arguments of philosophers. London, UK: Routeledge \& Kegan Paul.

Huang, K., Lee, Y. W., \& Wang, R. Y. (1999). Quality information and knowledge. Upper Saddle River, NJ: Prentice Hall

Ives, B. Hamilton, S. \& Davis, G. B. (1980). A framework for research in computer-based management information systems, Management Science (pre-1986), 26, 9.

Kofler, E. (1968). O wartosci informacji (On value of information), Panstwowe Wydawnictwa Naukowe $(P W N)$, Warsaw, Poland.

Kuhn, T. S. (1996). The structure of scientific revolutions ( $3^{\text {rd }}$ ed.). Chicago: University of Chicago Press.

Laudon, K. C., \& Laudon, J. P., (2007). Essentials of business information systems $\left(7^{\text {th }}\right.$ ed.). Upper Saddle River, NJ: Pearson/Prentice Hall.

Magee, B., (2000). The great philosophers: An introduction to western philosophy. Oxford, UK, Oxford University Press.

March, J. G., (1994). A primer on decision making - How decisions happen. New York: Free Press.

Mende, J., (2005). The poverty of empiricism, Informing Science Journal, 8, 189-210. Retrieved from http://inform.nu/Articles/Vol8/v8p189-210Mende.pdf

Nadler, G. (1982). Work systems design: The IDEAL concept. Homewood, IL: Richard D. Irwin.

O’Brien, J. A., \& Maracas, G. M. (2008). Management information systems ( $8^{\text {th }}$ ed.). Boston, MA: McGraw-Hill/Irwin.

Peirce, C. S., (1958). Collected papers of Charles Sanders Peirce (8 vols). Cambridge, MA

Shannon, C. E., \& Weaver, W. (1949). The mathematical theory of communication. Urbana, IL: University of Illinois Press.

Special Report - Best Business Programs - BEST PROGRAMS - SPECIALTIES. U.S. NEWS \&WORLD REPORT, August 28, 2006. See www.usnews.com

Wang, R. Y., \& Strong, D. M. (1996). Beyond accuracy: What data quality means to data consumers. Journal of Management Information Systems (JMIS), 12(4), 5-34. 


\section{Biography}

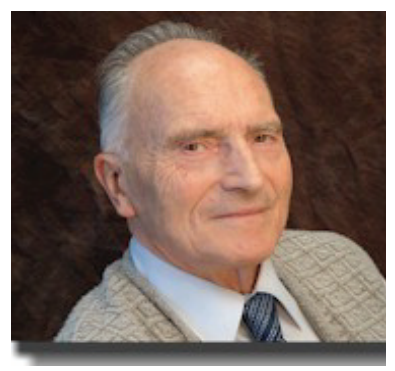

Zbigniew J. Gackowski has experience in industry, administration, and academia. It bridges his Central European and US experience in Computer Information Systems (Warsaw Polytechnic, University of Michigan [Fulbright Research Scholar], Purdue University [Visiting Associate Professor], Baruch College [Visiting Professor], California State University, Stanislaus [Professor], and the University of Melbourne [Visiting Professor]). In Poland, he has published 120 items (four books and six papers in refereed journals) and has presented 12 papers in Europe, the US, Middle East, and South America. In the

USA, he has taught at three universities and has presented 24 research papers that have been published in the proceedings of ASIS, ACM, DSI, Information Systems Educators Conference, The Informing Science Institute, and the International Conference on Information Quality at MIT. He is a member of ACM and DSI, a charter member of the Association for Information Systems, and a founding member of the Institute of Informing Science. His research focuses on informing and quality of data and information from the perspective of decision making in operations. 